\title{
DA NECESSIDADE DO DIVÓRCIO
}

\author{
Joaquim Penido Monteiro \\ Professor de Direito Civil da Faculdade de Direito \\ da Universidade do Paraná
}

Estudada a individualidade humana sob o seu aspecto sociológico, encontramos, desde os albores de sua existência conhecida, a irresistível tendência para a constituição do que chamamos hoje família. Primeiramente rudimentr, com direitos unilaterais, direitos baseados na fôrça física que proporcionava os esforços necessários à consecução dos alimentos, veiu sofrendo múltiplas e as mais variadas transformações, através dos povos e através as idades. Viveram os nossos antepassados, em tempo longo, more ferarum: com os costumes das féras, dos irracionais. Depois, com o aumento de civilização, cada povo adotou as suas leis e os seus costumes, pronunciando-se sempre e cada vez mais, a elevação moral na instituição que é, inegavelmente, a célula mater da sociedade. Para constituição da família legal, foi creado o instituto do casamento. Coexistente com êle, nos povos que adotaram o monoginismo, surgiu o concubinato, produto direto do instinto poligínico do homem. Do casamento e do concubinato são, em regra geral, produtos naturais os filhos.

Não hei de fazer o estudo consciencioso de tais questões, mas - pois que varietas delectat - respingarei aspectos, daqui e dali, o mais amenamente que puder.

Da família, Fustel de Coulanges disse o momento de transição entre a transitoriedade do contacto entre os elementos dos dois sexos, no gênero humano, e afirmou que o que unia os 
membros da família antiga era qualquer coisa mais poderosa do que o instinto genésico e o nascimento do filho, mais forte do que o sentimento e a fôrça física - era a religião do lar e dos antepassados.

A família, tal como a entendemos hoje, nasceu na Grecia, elevou-se em Roma.

Altamente interessante é o estudo de suas transformações.

Ora povos com instituições de promiscuidade; ora a poliginía legal; ora a monogínia, com o concubinato, ou legal, ou tolerado. Povos antigos e já civilizados - o chinês, por exemplo, adotando leis que davam a todos os filhos de um homem, fôssem êles quais fôssem, o direito à sucessão do pai pre-morto, com vantagens ao mais velho da mulher principal - posição social e consequentes dignidades. Igual disposição existiu entre os árabes. Todos eram filhos legítimos. Entre os hebreus, encontramos o caso de Abraão que, casando legalmente com Sara, porque era estéril, procurou sucessão no concubinato com Agar, sua escrava. No tempo da poligínia grega (combatida tenazmente pelo egípcio Cecrops, que se estabelecera na província Ática) os filhos naturais tinham o mesmo tratamento dos filhos legítimos. Exemplos: Hercules, Teseu, Aquiles, Pirro. Aliás, esta completa liberdade de costumes transparece em tôda mitologia grega, onde existia aquela que Virgilio cognominou dea amoris et pulchritudinis - Venus.

Em Atenas, entretanto, depois da legislação de Solon, os indivíduos, para gozarem de direitos civis, deveriam ser provenientes de cidadão e cidadã atenienses. $O$ filho natural não fazia parte da família de seu pai e nem podia ter função civil ou religiosa.

Em Roma, cuja fundação é atribuida aos dois gêmeos filhos de u'a mulher livre - lupa — os filhos naturais foram vulgo-quaesiti.

São as mais variadas as situações, quer do casal humano, 
quer do indivíduo - homem ou mulher - quer dos produtos das uniões sexuais.

A preocupação pelo estado em que viriam a ficar os filhos - vale dizer a preocupação pela infância - foi constante e forte, em todos os países e em tôdas as idades.

Em França, Jacques de Nouvion chegou a escrever que o legislador que levantasse a situação dos filhos naturais veria o seu nome ligado ao do século. Foi um dos inúmeros que jamais se conformaram com a injustiça da situação em que eram postas creaturas perfeitamente inocentes do fato de seus nascimentos.

Em Roma, nos anos 757 e 762, as condições dos filhos naturais foram muito melhoradas, em virtude das leis de Augusto, as que são citadas sob a denominação única - leges - - a Julia de maritandis ordinibus, de 757, e a Pappia Poppaea, de 762. Elas legalisaram os concubinatos e, consequentemente, os filhos de tais uniões havidos eram legítimos, ficando a situação de espúrios apenas para aqueles provindos de uniões proibidas. Assim foi até à época de Constantino, quando o concubinato deixou de ser reconhecido legalmente, passando os filhos de tais uniões à qualidade de naturais, que poderiam, como hoje, pela nossa lei, ser legitimados.

Salto brusco e confundente nos faz vêr a mesma Roma: da situação garantida, legal, até com direitos à sucessão paterna passarem os filhos naturais à situação de infames!... Houve época em que seriam postos fora da lei os senadores, os prefeitos, os decemviros, os ministros do culto que quizessem considerar legítimos os filhos havidos com mulher de condição proibida para o casamento. Foi ainda Constantino quem derrogou as leis de 757 e 762 e declarou o concubinato ilegal.

Sem querer ferir susceptibilidades, colocando-me no estrito ponto de observação dos fatos, constato constituir uma ironia o procedimento daquele governante, diante do característico 
com que passou à história - primeiro imperador cristão. As prédicas, os ensinamentos, os atos do Cristo, sempre cheios de inteligente justiça e de profundo sentimento de amor por tôdas as creaturas: a sua humaníssima indulgência deante da confissão da adúltera, prestes a ser lapidada, não se coadunariam com a situação de injusta inferioridade a que eram arremessados sêres isentos de tôda a culpa em seus nascimentos. Punir os filhos para proibir o concubinato aos pais é a cousa menos justa e menos cristã que se pode imaginar. Compreende-se tal procedimento do imperador cristão, se se observar o clima moral e intelectual daquele momento histórico. Era necessário implantar os novos princípios e as novas normas religiosas e morais; exerciam marcada ascendência os sacerdotes, os quais, com tôdas as fôrças, pugnavam contra os resíduos das antigas convenções e do antigo estatuto social. No ardor da campanha, é compreensível se hajam obliterado os raciocínios, dando lugar à eficiência de um estrabismo psíquico que conduziu a abusos de poder e a êrros de legislação, tendo culminado, no assunto que estamos perlustrando, com a lei de Leão VI, que, além de suprimir a legalidade do concubinato - nefaria consuetudo creou a classe os filhos ex damnato coitu nati. E tanto foi assim, e tanto a legislação prejudicial e injusta foi produto do clima do momento, que sob o império do mesmo Constantino, no ano 335 , surgiu a legislação ampliadora dos meios de reconhecimento dos filhos ilegítimos, sendo mantido o mais humano de todos - o subsequente casamento - modalidade que foi ao auge, permitindo a libertação da escrava concubina, para fins de casamento e legitimação do filho com ela havido.

Após o advento do cristianismo, com a legislação entregue aos clérigos, com idéias diametralmente opostas às anteriores, foi manifesto o combate às uniões naturais e à legalidade do concubinato. $O$ estudo da matéria mostra que são nìtidamente desencontradas as opiniões a respeito da tolerância ou do reconhecimento do concubinato, pelo direito canônico. Não é asado o momento para mais longo exame, nem é pròpriamente o concubinato o assunto dêste artigo, tão infelizmente desalinhavado. Não interessa saber se são autenticamente interpretadas e 
se são válidas as afirmativas que lemos nos livros, a respeito dos concílios de Toledo ou de Maiença ou de Tribur. 0 que é exato, o que todos nós de sobra sabemos, é que o direito canônico católico romano e a ação das diferentes seitas religiosas cristãs, tôdas elas combatem a convivência de homem e mulher formando apenas a família natural, ou seja (perante a nossa lei e nossa moral) o concubinato.

Pelo reconhecimento oficial do direito canônico, pela oficialização da igreja romana em Portugal e em nosso país, eram legais os casamentos celebrados pelos sacerdotes, até à entrada em vigor do decreto . $^{\circ} 181$, de 24 de janeiro de 1890 , regulamentado pelo de n..$^{\circ} 233$, de 27 de fevereiro seguinte.

Como era natural, não foi sem oposição que se implantaram as novas instituições e - questão de hábito ou de crenças ou de opinião política - bôa parte da população continuou a adotar apenas o casamento religioso. Isto provinha não só daquelas possíveis razões, como da ação - vou repetir as palavras do texto legal - de uma parte do cléro católico que, com atos de acentuada oposição e resistência à execução da lei, celebrava 0 casamento religioso e aconselhava a não observância da prescrição civil. Expondo assim os motivos, o decreto do Govêrno Provisório, n. ${ }^{\circ}$ 521, de 26 de junho de 1890, ordenou que o casamento civil fôsse celebrado antes de qualquer cerimonia religiosa de qualquer culto, estabelecendo a pena de seis mêses de prisão e multa correspondente à metade do tempo, com o dôbro na reincidência, para o ministro de qualquer confissão que celebrasse as cerimônias religiosas antes do ato civil. Êste decreto foi a medida enérgica que creou situações legais, deante dos continuados ataques e da resistência à execução das disposições civis, pois já em 11 de junho daquele mesmo ano, o ministro da Justiça (então o grande brasileiro Campos Sales) havia expedido aviso circular estabelecendo preceitos legais e recomendando a sua publicidade - cito o exórdio do aviso - afim de que os fanáticos ou ignorantes não induzam ou sejam induzidos à falsa opinião de que a lei do casamento civil reconhece para os seus efeitos outros casamentos que não o civil, resul- 
tando dêsse êrro graves e irremediáveis males em prejuizo da constituição da família e de importantes direitos. Sobrevindo a Constituição de 24 de fevereiro de 1891, logo surgiram discussões a respeito da revogação de leis e dispositivos anteriores. $\mathrm{E}$ o mal aceito decreto 521 (atacado principalmente como violador da liberdade de consciência) foi declarado revogado pelos parágrafos $4 .^{\circ}$ e $7 .^{\circ}$ do art. 72 da Constituição, como consta no aviso circular do Ministro da Justiça, (então o Barão de Lucena) de 15 de abril de 1891. Aquele aviso ministerial foi verdadeiramente o produto de um movimento da opinião do país que, católico em sua maioria absoluta e, além disto, habituado às normas do regime anterior, jamais havia aceito aquilo que era incessantemente proclamado como despótica violência à liberdade religiosa, que a liberalíssima Constituição estabelecera. Extinta a proibição da precedência do religioso à celebração do casamento civil, as condições especiais do nosso país trouxeram a consequência paradoxal de justamente os ministros religiosos, em suas funções, serem fatores da organização de famílias que são apenas naturais perante a lei civil.

Escrevo com perfeita isenção de ânimo, apenas diante da constatação dos fatos que são diuturnos, sobretudo na judicatura pelo interior.

Bem sei - e aplaudo sinceramente - que as autoridades eclesiásticas ensinam e determinam o conhecimento e a obediência à lei civil. As condições peculiaríssimas do nosso hinterland, entretanto, têm sido tais que essas determinações e êsses ensinamentos são inócuos. 0 analfabetismo generalizado, a ignorância das leis, a supersticiosidade em forma de religião, o primitivismo da vida material - condições inegàvelmente existentes e predominantes no interior brasileiro - produziram a situação verificada: ou simples uniões naturais, ou casados apenas rèligiosamente. Se os núcleos de povoação distam muito de arraiais ou de vilas ou de cidades, os pares apenas "se juntam"; se, vivendo menos afastados, encontram ministros religiosos, "casam-se" perante êles. Esta circunstância é comum, porque ou vigários ou ministros de variadíssimas seitas fazem 
excursões pelos seus territórios e há sempre ou capela ou a casa do mais bem colocado dos crentes para os ofícios religiosos. Naqueles meios ambientes, as situações ficaram perfeitamente regularisadas, pois alí nem ocorre que do casamento haja tantas e tão sérias consequências jurídicas. Ir ao cartório da séde do distrito é não sòmente trabalhoso pela viagem, como as conversas com o escrivão, as explicações a serem dadas, a exibição de documentos e as despesas que aparecem ficam constituindo impecilho invencível para a realisação do casamento civil.

Para obviar tais inconvenientes, o Govêrno da República promulgou leis que regulamentam o casamento religioso com efeitos civís. É medida francamente elogiável pela sua intenção. A prática, porém, não tem correspondido à expectativa.

Com a preocupação de não me alongar em demasia, passo a outro fator de concubinatos, de existência relativamente recente. Refiro-me aos chamados "casamentos por contrato", "casamentos no Uruguai", "casamentos no México".

É já velha e sempre foi muito debatida no Brasil a chamada questão do divórcio a vínculo.

Tomando, para desenvolvimento dos raciocínios dêste momento, apenas o que de fato existe como lei, vamos encontrar os dispositivos do Código Civil, vigorando desde $10^{\circ}$ de janeiro de 1917, no livro I de sua parte especial.

A família, fenômeno natural, que antecede ao casamento, fenômeno legal, fica constituida pela assinatura e efetivação de um contrato civil todo especial, único. Não é distratável em sua essência. No decreto 181, de 24 de janeiro de 1890, que foi a primeira lei reguladora do casamento civil, encontramos o atual desquite com o nome de divórcio e os artigos 27 e 88 dando, nìtidamente, a característica de perenidade até hoje mantida. Naquele artigo, a lei mandava que ambos os cônjuges declarassem receberem-se por marido e mulher enquanto vivessem. Nêste, no 88, a lei dizia: o divórcio não dissolve o vínculo con- 
jugal, mas autoriza a separação indefinida dos corpos e faz cessar o regime dos bens, como se o casamento fôsse dịssolvido. $\mathrm{O}$ pensamento e a orientação são os mesmos existentes agora no Código Civil, nos diferentes artigos do capítulo primeiro e do título IV, do livro I, na parte especial. Assim é que o § un. do art. 315 diz que o casamento válido só se dissolve pela morte de um dos cônjuges e que não ficará dissolvido nem trinta anos depois de passada em julgado a sentença que concedeu abertura de sucessão provisória, nem que, dado um cônjuge com 80 anos de nascido, quando dêle ainda se sabia, tenham decorrido 5 anos sem qualquer notícia; e o art. 322 diz que a sentença do desquite autoriza a separação dos cônjuges e põe têrmo ao regime matrimonial dos bens, como se o casamento fôsse dissolvido.

Vivendo assim, sob um direito todo convencional; enclausurado dentro de princípios que, por mais sancionantes, mais punitivos, não anulam, não podem anular os ímpetos e os atos do ser humano, acionados pelos seus instintos e seus reflexos psíquicos; vivendo sob tais normas jurídicas, o cidadão brasileiro, homem ou mulher, uma vez malogrados os seus anseios de felicidade na vigência da sociedade que, procurando ser feliz, organisára, viu-se na contingência ou de viver em isolamento afetivo, ou de constituir ambiente de afetividade e de satisfação do funcionamento orgânico, arrostando a reprovação de seu ambiente social, vencendo, muitas vêzes, suas próprias convicções baseadas na moral convencional: celibatarismo ou concubinagem. Para o celibatarismo é preciso vocação e o estado de cuncubinagem é clamoroso, constitue escândalo social, leva os seus adotantes ao opróbio, à execração, à desclassificação social. Raros, por isso, aqueles que, pertencendo ao meio social mais culto, se arriscam a, ostensivamente, constituir ou contribuir para a constituição de família natural.

É velho o brocardo "a necessidade põe a lebre a caminho". E velho e muito verdadeiro...

Não sendo (senão difìcilmente) vencíveis os pendores na- 
turais; sendo demasiado penosos tanto o isolamento físico e afetivo, como o opróbio público, os interessados (geralmente os desquitados ou os simplesmente separados de fato, hoje em dia já muito numerosos também na classe abastada) "se puzeram a caminho" e encontram, no conselho dos entendidos, a constituição da sociedade universal, estabelecida pelo art. 1368 do Código Civil. E temos hoje - quem pode negar? - número já apreciável de "casais" cujos interêsses estão protegidos por contratos onde não aparece - et pour cause - menção do lado verdadeiro da sociedade estabelecida, ou seja à vida marital e à constituição da família que é, jurìdicamente, família natural.

Ao lado dêstes, isto é, dos casamentos por contrato, temos os casamentos subsequentes a divórcios - leiamos bem - DIVóRCIOS - processados ou no Uruguai, ou no México. Os jornais trazem anúncios, com a afirmativa da garantia de ulterior casamento. Ora, nenhum brasileiro, casado vàlidamente pela lei brasileira, pode ter o vínculo conjugal completamente dissolvido, enquanto viver. Mas - disse Plinio Barreto, escritor e jurista dos melhores, em espirituosa crônica - a viagem ao Uruguai, país, além de amigo, muito visinho, pode ser "camouflada" por um estágio de quinze dias ou vinte dias dentro de uma casa ou de apartamento, surgindo o novo "par" perfeitamente estabelecido na sociedade, com papéis em ordem, pelo casamento realizado... no México... É que, às vêzes, a agência fornecedora das certidões, não tendo "documentação" uruguáia, tinha papéis mexicanos que... também serviam... Estão "casados", está respeitado o preconceito social, está regularizada a situação...

Para elucidar esta dissertação, árida pelo assunto e enfadonha pelo autor, vou apresentar casos concretos, conhecidos e sabidos, em nossa atual sociedade. Dêles decorrem efeitos. Efeitos morais e efeitos jurídicos. Não representam - em meu modo de pensar - mais que um passo na evolução das instituições sociais humanas. Charles Letourneau, na edição de 1888 de seu excelente "L'évolution du mariage et de la famille", termina o livro com palavras e pensamentos que podem ser, com justeza, 
aplicados neste nosso momento. Disse êle que as perspectivas que, naquela época, desconcertavam os espíritos conservadores não eram, em última análise, senão a última consequência da evolução milenar. Os estadistas não evolucionistas constatam, sem poder compreender o fato, que a indissolubilidade do vínculo conjugal se torna cada vez mais intolerável aos indivíduos. Existe uma como que maré de discórdia que torna cada vez mais precária a estabilidade conjugal. Êste desagradável estado de coisas desola, por outro lado, os moralistas que, também êles, não n'o sabem explicar. 0 espanto daqueles e as lamentações dêstes não têm justificação. É apenas o futuro que, com sua desenvoltura habitual, quer sair do passado. Gritam que tudo vai acabar. Absolutamente! Apenas tudo vae ser renovado, vae ser transformado. Desde a maior distância no tempo, desde a idade da pedra, a história da humanidade não passa de longa série de renovações, de reformas. Bem ao invêz de nos afligirmos, quando o mundo entra em um período de parturição, nós nos devemos alegrar e repetir, com Lucrécio

\section{Cedit enim rerum novitate extrusa vetustas}

Semper et ex aliis aliud reparare necesse est.

Há metamorfoses em tudo; sempre nova onda expele as antiqualhas e a eterna transformação rejuvenecendo o universo.

Não podemos deixar de constatar que, com a humanidade, caminham as convenções sociais e as normas jurídicas. Das formas poligínica e poliândrica do casamento, viemos à do nosso direito: manogínica e monândrica, monogâmica. A monogamia (emprego aqui o vocábulo no seu sentido gramatical, de um só casamento), o casamento único da vida do indivíduo, homem ou mulher, tem sua base nos preconceitos religiosos e é resquício da preponderânria do direito canônico. As instituições jurídicas, para serem aceitas, para não serem desobedecidas ou burladas, não devem contrariar os anhelos, os pendores da psiquê, traduzidos pelos atos tanto instintivos como volitivos.

Não vou detalhar as condições dos componentes das sociedades conjugais (sobretudo as condições da mulher) entre os 
trogloditas, entre os antigos árabes, entre os agatirsos, ansos, garamantos, chinêses, indús, adamanitas, nasamões, ilhéos baleares, cambodgianos, polinésios, malasianos, abissínios; nem, tão pouco, descer a detalhes para recapitular a história dos judeus, dos romanos, dos gregos; nem do feudalismo; nem me demorar a citar versículos dos livros sagrados ou a relatar episódios ali descritos.

Hei, porém, de, antes de terminar, aludir a um aspecto de perfeita atualidade, relativo às questões às quais me venho referindo.

Relembrado quão profundamente estão modificadas as situações quer da mulher, quer da criança; relembrando que a mulher, no casamento, passou de simples coisa de valor comerciável à categoria de espôsa, companheira de vida para o homem, sua igual em direitos; recordando que os filhos eram, na maioria dos povos antigos, despidos de direitos e carregados de deveres, sendo, por exemplo em Roma, o pater familias senhor absoluto dentro de sua casa (qui in domo dominium habet, no texto do Digesto) ; recordando estas fases da constituição social e jurídica da humanidade, quero - repito - pôr em relêvo o que se verifica em nosso país, no momento atual.

As leis da biologia, continúo a dizer, são eternas, são iniludíveis e são inilidíveis.

O casamento é apenas a forma adotada, sancionada pela lei para a efetivação, na sociedade organizada, daquilo que a contextura biológica (quer física, material, quer psíquica) dos indivíduos a êles impele, dêles exige, através a satisfação dos instintos de conservação do indivíduo e da espécie. Assim, está bem visto, o casamento, ou seja a conjunctio maris et foeminae, na sua forma legal estabelecida, para ser aceita e praticada, jamais se poderá afastar da constituição sobretudo psíquica dos indivíduos, constituição essa que é resultante do que fôr geralmente aceito e praticado pelo meio ambiente. Quem, no momento atual, antre as classes cultas, poderá ter ainda a ilusão de que os povos aceitam e praticam um idealismo refreador dos 
movimentos egoísticos tendentes à comodidade e ao prazer? Os moralistas clamam e afirmam o rebaixamento do nível moral e se lastimam e oferecem soluções e pedem meios coercitivos e apontam o abismo de desorganização em que a humanidade submergirá. Embalde! Mais horas do sol que desejam não conseguirão êsses Josués da suposta moral e dos supostos bons costumes. 0 cientista, o observador imparcial e livre de preconceitos verifica que, máu grado clamores e objurgatórias, a sociedade adota novos hábitos, aceita novas situações, afaz-se a novas normas e, novo Galileu, o jurista constata e anota e pur se muove - bem certo de que o fato novo em breve será assimilado e se individuará em texto legal. Sim, porque o legislador muitas vezes não é mais que o transportador do uso e do costume para a contextura e vigor da lei.

Venho dizendo sôbre o casamento, sôbre o concubinato e suas consequências, ou sejam os filhos. Já não posso - eis que bem longo já estou - apresentar um relato das situações entre os filhos legítimos e os naturais, assim como entre os efeitos do casamento e do concubinato. Seria interessante percorrermos as diversas legislações, mas não haveria correspondência entre o tempo e a fadiga dos leitores.

Dos aspectos que mais curiosamente chamam a atenção dos que se preocupam com os fatos de nossa atual legislação, respigo o seguinte: tanto o código civil como a moral social reconhecem, no Brasil, apenas o casamento legal como fator da família legítima. 0 concubinato, entretanto, não é fato delituoso, mas (assim mesmo em nem tôdas as camadas da sociedade) simplesmente fato ilícito, porque contrário aos sãos costumes e à bôa ordem social; é situação de fato, da qual decorrem certas consequências. A lei não pode (pelo menos por enquanto) acoroçoar, incentivar, animar a tendência às uniões livres. Digo "não pode", não sòmente pela nossa estrutura social e pelas idéias religiosas da inegável maioria do povo, como porque "não deve", pois os resultados do sistema de uniões livres e de facilidade do divórcio e de divórcio pela simples vontade de um dos cônjuges (que a Russia Soviética havia adotado, 
mas já revogou) são de consequências verdadeiramente funestas, para todos. Ora, assim sendo, a coexistência do casamento indissolúvel e dos dispositivos legais favoráveis aos filhos ilelítimos são - a mim me parece - o incentivamento ao concubinato, o reconhecimento do concubinato, especialmente dos desquitados ou dos separados de fato.

Não fechemos os olhos. Os fatos existem e são numerosos.

Mui de ser aplaudido é o comentário do erudito Carvalho Santos ao art. 1719 do Código Civil, sôbre a concubina do testador casado. Nada de ilusões ou de fantasmagorias. Enxerguemos a vida real, percebamos os seus aspectos, vejamos 0 que realmente se passa. Os fatos são eloquentes, são eloquentíssimos.

Deveremos permanecer silenciosos, impassíveis deante da existência de um dispositivo legal que está em contrário à formação biológica, que flagrantemente contraria os resultados dos complexos psíquicos dos indivíduos?

Os advogados; os militantes do fôro, os propugnadores da aplicação das leis; os confidentes dos mal casados, os seus conselheiros, quantas vêzes haverão sentido e sentirão a angústia da improficuidade do saber e do trabalho, impossibilitados que estão para, verdadeiramente, regularizar situações essencialmente humanas, situações pungentemente irremediáveis. Poderão dar aspecto "tolerado" pela sociedade. Não poderão, entretanto, estabelecer o exato equilíbrio, a consolidada firmeza dos direitos. Aconselharão contratos, redigirão cláusulas, atenderão a futuras situações, mas ficarão sempre na ansiedade da eficiência dos esforços, visto como (tudo pode acontecer entre dois sêres que têm vida comum) a liquidação das cláusulas contratuais será sempre coisa penosa e, mais que tudo, incerta. Isto relativamente aos dois contratantes. E quanto a terceiros?! Quanta demanda, quanta impugnação! Deus louvado, a jurisprudência e a legislação social brasileiras estão nìtidamente norteadas para o reconhecimento dos direitos decorrentes dos laços de afetividade. A companheira, a teúda inscrita na car- 
teira profissional é equiparada à espôsa para os efeitos de recebimento da indenização pelos acidentes de trabalho. Os filhos, de qualquer condição, já são beneficiados por uma legislação própria, como de igual pelas leis de assistência social. São-lhes garantidos direitos, sim. Mas é preciso que tenham sido reconhecidos como filhos ou, então, que proponham ou hajam proposto ações de investigação de paternidade e que vençam ou hajam vencido nestas ações. Situação evidentemente difícil, periclitante. E as mães dêstes filhos? Embora hoje - e apláudo a duas mãos - a magistratura brasileira, pelos seus mais autorizados representantes, quer tribunais, quer juizes singulares (entre os quais, no Paraná, está Ernani Guarita Cartaxo, em muito lúcida sentença), embora a magistratura brasileira reconheça direitos às concubinas, quanto a legados testamentários de homens solteiros e de desquitados, ficam estas creaturas (muitas vêzes companheiras virtuosíssimas, perfeitas mães de família) sempre sujeitas às investidas dos interêsses de terceiros e se tiveram a infelicidade de ser felizes na companhia de um homem casado, estarão literalmente excluidas dos benefícios, na sucessão! Isso me parece profundamente injusto. Vençamos os preconceitos; encaremos os fatos com realismo; reconheçamos que é necessário ser estabelecido — sem tardança o divórcio a vínculo.

Respeito, sincera e profundamente, tôdas as alheias opiniões. Sei que os católicos romanos consideram o casamento res sacra, sendo o seu vínculo obra diretamente divina e, portanto, não destrutível por obra humana. Aos juristas católicos apresento a realidade eloquente das situações, verificáveis a cada passo e em cada canto do nosso país. Se o direito canônico não admite o concubinato, havendo sido combatido a interpretação que jurisconsultos de nomeada deram ao conhecido canon do concílio de Toledo, "si quis non habet uxorem et pro uxore concubinam habet"; se Santo Agostinho, com tôda a sua grande autoridade, estabeleceu "concubinas habere non licet vobis, etsi non habetis uxores; tamen non licet vobis habere concubinas quas postea dimitatis et ducatis uxores"; se a moral da igreja católica, baseada no sexto mandamento da Lei de Deus, 
não admite a função sexual sem a bênção sacramental, forçoso é os próprios católicos reconhecerem que a mentalidade dos povos não ficou imobilizada no preceito nem no temor religioso e, nêste caso, parece preferível concordarem também êles na possibilidade de legalização, ao menos de legalisação leiga, de tantas uniões que, estando em franca divergência com os princípios da igreja, estão sob os inconvenientes de estado civil irregular. Não sugiro. Dou, apenas, o meu modo de encarar o problema existente. Não abro, não quero abrir discussões que se podem transformar em disputas. Estou me valendo dêste momento, sòmente para pedir a todos os juristas, assim aos divorcistas, como aos adversários do divórcio, que atentem para o problema social e, para a sua solução - favorável ou contrária - envidem seus esforços. Não nos esqueçamos de que o amor, além de físico, é, no sêr humano, esplendente e esplêndida evidência do Infinito e inapreensível Alfa-Oméga, do qual somos manifestação. Amemos o amor; respeitemo-lo; reconheçamos-lhe os direitos. Os poetas todos sabem - são filósofos que cantam. Um dêles, dos maiores, Miguel Zamacoïs, no encantador "Les Bouffons", disse profundas verdades humanas que Lacerda Pinto, êste duplo de perfeito poeta e perfeito jurista, traduziu assim:

... O espírito fraterno

Quem vem para relêr conosco um poema eterno,

No instante em que também chegamos a supôr

Que, embora repetindo, inventamos o amor!

... Pr'a levantar a triste humanidade

Veiu do céu esta palavra de piedade.

Anatema! dissera o céu que se inflamara;

Ama! disse depois. Palavra doce e clara!

Por ela, que mudou um réprobo em eleito,

Perdoou a terra ao céu o mal que êle tinha feito!

Que vem a ser o amor?

... Sábios e rimadores

Têm gasto éstro e saberes por exprimir-lhe as côres!

Do bem ou do mal que êle nos traz ao coração,

Nada diz a palavra, e menos a razão.

É um bem que se maldiz, é um mal que a gente adora, 
É um veneno mortal de que inda mais se implora!

Vida e morte, igualmente, a ambas êle apelida:

Um "não" contém a morte, está num "sim" a vida.

Se está triste a nossa alma, ou se está jubilosa,

O amor é o sol obscuro ou a sombra luminosa!

É alta fôrça que faz juntarmos nossas mãos,

A muralha transpondo aos preconceitos vãos.

Amar é deparar em nossa estrada um sêr

Que para o nosso amor deveria nascer!

Um semblante ignorado e que se reconhece

Quando êle, misterioso, aqui nos aparece!

Que, uma vez escolhido, exércitos despreza,

Despreza das prisões a invencível bruteza,

E, a despeito dos bens, da posição social, Se alcança!

Reconheçamos os direitos do maior dos sentimentos humanos e, adotando tôdas as precauções contra os possíveis e esperados abusos, pugnemos, os que estiverdes de acôrdo, pelo estabelecimento em lei do instituto do divórcio, do qual, se males decorrerem, serão menores, para pais e para filhos, que o atual reconhecimento do concubinato. 